\title{
Identification of Resistance to Fusarium oxysporum f. sp. niveum Race 2 in Citrullus lanatus var. citroides Plant Introductions
}

W. Patrick Wechter ${ }^{1}$, Chandrasekar Kousik, Melanie McMillan, and Amnon Levi

U.S. Vegetable Laboratory, United States Department of AgricultureAgricultural Research Service, 2700 Savannah Highway, Charleston, SC, 29414

Additional index words. watermelon, fusarium wilt, soilborne disease

\begin{abstract}
Fusarium wilt (FW) is a major disease of watermelon in North America and around the world. Control of this disease is difficult because the soilborne causal agent Fusarium oxysporum f. sp. niveum (Fon) produces chlamydospores that remain infectious in the soil for many years. Although various levels of resistance to Fon Races 0 and 1 exist in watermelon cultivars, no resistance to Race 2 or 3 has been reported. In this study, we used seed and seedling inoculation procedures to screen 110 U.S. PIs of wild watermelon (Citrullus lanatus var. citroides) for resistance to Race 2 FW. Of these 110 accessions, 15 showed significantly higher resistance to $F$ on Race 2 than that found in the watermelon cultivars Sugar Baby or Charleston Grey as well as in the C. lanatus var. citroides PI 296341 that was reported to contain resistance to FW. PI 271769, another C. lanatus var. citroides that was previously reported as containing resistance to $\mathrm{FW}$, is among the 15 resistant accessions described here. These 15 accessions are potential sources for resistance to Race $2 \mathrm{FW}$ in watermelon breeding.
\end{abstract}

Fusarium wilt [caused by Fusarium oxysporum Schlechtend.:Fr. f. sp. niveum (E.F. Sm.) W.C. Snyder \& H.N. Hans (Fon)] is one of the most serious soilborne diseases of watermelon (Martyn, 1985, 1987; Netzer, 1976). Initial symptoms can vary with chlorosis of leaves being common followed by asymmetrical wilting for the plant. When infection takes place in seedlings, noticeable stunting of the plant occurs followed by chlorosis and death. Necrosis of the stem, in the form of brown streaks in the vascular system produced by both the fungal exudates as well as the dying plant tissues, are characteristic of FW. Although the formae speciales (f. sp.) designation implies host specificity at the species level, there are numerous reports of cross-species and cross-genus level pathogenic interactions in f. sp. niveum as well as other fusarium isolates collected from different cucurbits in laboratory studies (Bouhot, 1981; Owens, 1955, 1956; Zhou and Everts, 2003, 2007). In addition, considerable variability in virulence and vegetative compatibility occurs among isolates within this formae speciales (Larkin et al., 1990; Zhou

\footnotetext{
Received for publication 27 Sept. 2011. Accepted for publication 5 Jan. 2012.

The contents of this publication do not necessarily reflect the views or policies of the USDA nor does the mention of trade names, commercial products, or organizations imply endorsement by the U.S. Government.

${ }^{1}$ To whom reprint requests should be addressed; e-mail Pat.Wechter@ars.usda.gov.
}

and Everts, 2007). Currently, there are four described pathogenic Races, 0, 1, 2, and 3 (Martyn and Netzer, 1991; Netzer, 1976; Netzer and Martyn, 1989, Zhou et al., 2010). Resistance to Fon Races 0 and 1, but not to Races 2 or 3, was incorporated into various commercial watermelon cultivars. The Fon Race 2 is considerably more virulent than Race 0 or 1 and infects all watermelon cultivars. Apart from being a soilborne pathogen, Fon is also a seedborne pathogen (Boughalleb and El Mahjoub, 2007; Michail et al., 2002). It can rapidly spread in watermelon production areas and has been reported to reduce yield by $40 \%$ in watermelon fields in the southeastern regions of the United States (Keinath et al., 2010). Fon Race 2 has been reported in Texas, Oklahoma, Florida, Maryland, Delaware, Georgia, Indiana, and South Carolina (Bruton et al., 1988, 2008; Bruton and Damicone, 1999; Egel et al., 2005; Keinath and DuBose, 2009; Martyn, 1985; Martyn and Bruton, 1989; Zhou and Everts, 2001, 2003).

Effective control of this disease has been achieved by the use of preplant soil fumigants. Recently, the most economical and effective fumigant, methyl bromide, has been withdrawn from the market, leaving no effective alternatives for control of this fungus with conventional chemicals. Fon produces chlamydospores that remain dormant in the soil for many years (Martyn, 1996), and there are no alternative fumigants that are as effective as methyl bromide in controlling these dormant spores. For this reason, standard chemical rotation strategies are not effective in controlling this soilborne disease. Finding resistant germplasm sources and incorporating the resistance into watermelon cultivars should be the most effective strategy for controlling FW in watermelon.

Two U.S. PIs of Citrullus lanatus var. citroides (PI 296341 and PI 271769) have been reported as resistant to Race 2 of Fon (Dane et al., 1998; Martyn and Netzer, 1991). An improved line of PI 296341, 296341-FR, has since been released by the Texas Agricultural Experiment Station (Martyn and Netzer, 1991). PI 271769 was identified by Dane et al. (1998) as resistant to Fon Race 2. A third watermelon PI, which was reported to be highly resistant to Fon Race 2 by Boyhan et al. (2003) with a rating of 0.9 from a 9-point rating scale, may actually be $\mathrm{Cucu}$ mis melo var. melo according to the Genetic Resources Information Network web site (http://www.ars-grin.gov) and as such would not normally be considered a host to this formae speciales of Fusarium oxysporum. Each of these screens uses slightly different methods and different isolates of Fon Race 2. The agreement among these three surveys is that the majority of watermelon accessions are highly susceptible to this race of the pathogen; unfortunately, these studies do not find unanimity as to the lines identified as resistant. In fact, the accession PI 296341, found to be the most resistant by Netzer and Martyn (1989), was found to be quite susceptible in the other two studies. What does appear evident from these surveys is that there are varying levels of resistance in the watermelon germplasm accessions and that there is distinct heterogeneity for this resistance within the individual accessions. Based on the considerable differences in findings of these three surveys, a new survey was justified that used aggressive inoculation techniques and focused on accessions that exhibited a uniformly high level of resistance or had a high frequency of resistant individual in previously published surveys. The C. lanatus var. citroides PI collection at the USDA, ARS Plant Genetic Resources and Conservation Unit (PGRCU; Griffin, GA) represents wide genetic diversity and is a valuable source for pest resistance genes for use in watermelon breeding (Jarret et al., 1997; Levi et al., 2001, 2011; Thies and Levi, 2007). The objective of this study was to evaluate the USDA, ARS C. lanatus var. citroides PI collection for resistance to Fon Race 2 (using a seed inoculation procedure in addition to a root inoculation procedure) and identify the most resistant accessions that could be useful for enhancing Fon Race 2 resistance in watermelon cultivars.

\section{Materials and Methods}

Plant materials. Citrullus lanatus var. citroides $\mathrm{PI}$ accessions were obtained from the PGRCU in Griffin, GA. One hundred ten, of the total 133, accessions in the collection were included in these tests (Table 1). In addition to these accessions, the watermelon cultivars Sugar Baby and Charleston Grey 
Table 1. Mean percent survival of Citrullus lanatus var. citroides accessions in response to Fusarium oxysporum f. sp. niveum Race 2 in two greenhouse tests. ${ }^{\mathrm{z}}$

\begin{tabular}{|c|c|c|c|c|c|c|c|c|}
\hline Accession & $\begin{array}{c}\text { Survival }^{\mathrm{y}} \\
(\%)\end{array}$ & & Accession & $\begin{array}{c}\text { Survival } \\
(\%)\end{array}$ & & Accession & $\begin{array}{c}\text { Survival } \\
(\%)\end{array}$ & \\
\hline PI482246 & 56.3 & $a^{x}$ & PI500335 & 7.1 & ef & PI482315 & 0.0 & $\overline{\mathrm{f}}$ \\
\hline PI482252 & 56.3 & $\mathrm{a}$ & PI505604 & 7.1 & ef & PI482321 & 0.0 & $\mathrm{f}$ \\
\hline PI255136 & 53.6 & $\mathrm{a}$ & PI532624 & 7.1 & ef & PI482322 & 0.0 & $\mathrm{f}$ \\
\hline PI296335 & 50.0 & $\mathrm{a}$ & PI532664 & 7.1 & ef & PI482324 & 0.0 & $\mathrm{f}$ \\
\hline PI482279 & 50.0 & $\mathrm{a}$ & PI532668 & 7.1 & ef & PI482326 & 0.0 & $\mathrm{f}$ \\
\hline PI482282 & 50.0 & $\mathrm{a}$ & PI532738 & 7.1 & ef & PI482333 & 0.0 & $\mathrm{f}$ \\
\hline PI482331 & 46.7 & $a b$ & PI596659 & 7.1 & ef & PI482334 & 0.0 & $\mathrm{f}$ \\
\hline PI271779 & 43.8 & $\mathrm{ab}$ & PI596668 & 7.1 & ef & PI482335 & 0.0 & $\mathrm{f}$ \\
\hline PI296339 & 43.8 & $a b$ & PI244019 & 6.3 & ef & PI482336 & 0.0 & $\mathrm{f}$ \\
\hline PI299379 & 43.8 & $a b$ & PI270563 & 6.3 & ef & PI482338 & 0.0 & $\mathrm{f}$ \\
\hline PI482273 & 43.8 & $a b$ & PI295850 & 6.3 & ef & PI482342 & 0.0 & $\mathrm{f}$ \\
\hline PI482276 & 43.8 & $a b$ & PI296342 & 6.3 & ef & PI482355 & 0.0 & $\mathrm{f}$ \\
\hline PI482277 & 43.8 & $a b$ & PI296343 & 6.3 & ef & PI482361 & 0.0 & $\mathrm{f}$ \\
\hline PI271769 & 40.2 & $a b c$ & PI299378 & 6.3 & ef & PI482379 & 0.0 & $\mathrm{f}$ \\
\hline PI270564 & 33.0 & $a-d$ & PI379243 & 6.3 & ef & PI485581 & 0.0 & $\mathrm{f}$ \\
\hline G15896 & 18.8 & $b-e$ & PI482283 & 6.3 & ef & PI500331 & 0.0 & $\mathrm{f}$ \\
\hline G15897 & 18.8 & $b-e$ & PI482298 & 6.3 & ef & PI500332 & 0.0 & $\mathrm{f}$ \\
\hline PI189225 & 18.8 & $b-e$ & PI482307 & 6.3 & ef & PI500334 & 0.0 & $\mathrm{f}$ \\
\hline PI270562 & 18.8 & $b-e$ & PI482311 & 6.3 & ef & PI500354 & 0.0 & $\mathrm{f}$ \\
\hline PI271771 & 18.8 & $b-e$ & PI482316 & 6.3 & ef & PI525083 & 0.0 & $\mathrm{f}$ \\
\hline PI482257 & 18.8 & $\mathrm{~b}-\mathrm{e}$ & PI485583 & 6.3 & ef & PI532659 & 0.0 & $\mathrm{f}$ \\
\hline PI482309 & 15.5 & cde & PI500308 & 6.3 & ef & PI532666 & 0.0 & $\mathrm{f}$ \\
\hline PI271767 & 13.4 & cde & PI512854 & 6.3 & ef & PI542113 & 0.0 & $\mathrm{f}$ \\
\hline PI542117 & 13.4 & cde & PI525081 & 6.3 & ef & PI542114 & 0.0 & $\mathrm{f}$ \\
\hline PI596662 & 13.4 & cde & PI542123 & 6.3 & ef & PI542118 & 0.0 & $\mathrm{f}$ \\
\hline PI597691 & 13.4 & cde & PI596653 & 6.3 & ef & PI542119 & 0.0 & $\mathrm{f}$ \\
\hline PI244017 & 12.5 & de & PI597677 & 6.3 & ef & PI596656 & 0.0 & $\mathrm{f}$ \\
\hline PI296334 & 12.5 & de & PI597696 & 6.3 & ef & PI596665 & 0.0 & $\mathrm{f}$ \\
\hline PI296337 & 12.5 & de & CHASGRY & 6.3 & ef & PI596666 & 0.0 & $\mathrm{f}$ \\
\hline PI296341 & 12.5 & de & PI179881 & 0.0 & $\mathrm{f}$ & PI596667 & 0.0 & $\mathrm{f}$ \\
\hline PI482261 & 12.5 & de & PI244018 & 0.0 & $\mathrm{f}$ & PI596669 & 0.0 & $\mathrm{f}$ \\
\hline PI482265 & 12.5 & de & PI255137 & 0.0 & $\mathrm{f}$ & PI596670 & 0.0 & $\mathrm{f}$ \\
\hline PI482300 & 12.5 & de & PI271770 & 0.0 & $\mathrm{f}$ & PI596671 & 0.0 & $\mathrm{f}$ \\
\hline PI482303 & 12.5 & de & PI271775 & 0.0 & $\mathrm{f}$ & PI597675 & 0.0 & $\mathrm{f}$ \\
\hline PI597676 & 12.5 & de & PI288316 & 0.0 & $\mathrm{f}$ & PI606135 & 0.0 & $\mathrm{f}$ \\
\hline PI596658 & 8.3 & ef & PI295842 & 0.0 & $\mathrm{f}$ & SBABY & 0.0 & $\mathrm{f}$ \\
\hline PI271773 & 7.1 & ef & PI482308 & 0.0 & $\mathrm{f}$ & & & \\
\hline PI500303 & 7.1 & ef & PI482312 & 0.0 & $\mathrm{f}$ & & & \\
\hline
\end{tabular}

${ }^{z}$ Total number of inoculated seedlings per accession ranged from five to 16

yPercent survival for each PI is the mean of two evaluations.

${ }^{\mathrm{x}}$ Means followed by the same letter are not significantly different $(P=0.05)$

CHASGRY = Watermelon cultivar Charleston Grey, moderately susceptible control; SBABY= Watermelon cultivar Sugar Baby, highly susceptible control.

were included as highly susceptible and moderately susceptible controls, respectively. PI 271769 was used as the resistant control in all tests (Dane et al., 1998).

Fungal isolate and growth conditions. Fusarium oxysporum f. sp niveum (Fon) Race 2 B05-30 (kindly provided by Anthony Keinath, Clemson University) was originally isolated from a watermelon plot at Clemson University's Coastal Research and Educational Center in Charleston, SC. The isolate was confirmed to be Race 2 by use of differentials as described by Keinath and DuBose (2009). The Race 2 Fon isolate was maintained on potato dextrose agar (PDA) plates. Isolates were grown under a 12-h diurnal lighting regime using high-intensity fluorescent lighting at $26 \pm 2{ }^{\circ} \mathrm{C}$. Inoculum for tests was generated by placing four $1-\mathrm{cm}$ mycelium/agar plugs from a 10-d-old PDA plate into 500-mL Erlenmeyer flasks containing $200 \mathrm{~mL}$ potato dextrose broth. The liquid cultures were grown on a bench shaker at $200 \mathrm{rpm}$ under a 12-h diurnal lighting regime using high-intensity fluorescent lighting at $26 \pm 2{ }^{\circ} \mathrm{C}$ for $14 \mathrm{~d}$. At $14 \mathrm{~d}$, the mycelia/conidia culture suspension was filtered through three layers of cheesecloth followed by a final filtration through a single layer of Miracloth (EMD Chemicals, San Diego, CA). Conidia were quantified using a hemacytometer. The conidial suspension was adjusted to a final concentration of $1 \times$ $10^{6}$ conidia $/ \mathrm{mL}$ with sterile distilled $\mathrm{H}_{2} \mathrm{O}$.

Plant growth and fungal inoculations. A modified version of the inoculation method of Dane et al. (1998) was used as follows: eight seeds were sown into a 1:1:1 (v:v:v) mixture of Metromix 360 (The Scott's Co., Maryville, $\mathrm{OH}$ ), autoclaved sand, and vermiculite (Therm-O-Rock, New Eagle, PA) in 50-cell plug trays (T.O. Plastics, Clearwater, $\mathrm{MN})$. Each cell was then inoculated by pipette with $20 \mathrm{~mL}$ of this inoculum suspension. Only one seed was planted per cell. Eight seeds of each accession were planted per test separated in two blocks of four seed each. Each plug tray was placed in a $56 \times 28 \times 5-\mathrm{cm}$ containment tray and then placed on the greenhouse bench where temperatures ranged from 27 to $32{ }^{\circ} \mathrm{C}$. Seedlings were watered from the bottom as needed to maintain a moist soil mix. Seedlings were re-inoculated with an additional $15 \mathrm{~mL}$ of fresh inoculum prepared as described $14 \mathrm{~d}$ after seeding. Plants were rated as dead or alive after $21 \mathrm{~d}$. The screen was repeated.

Surviving plants of the best performers (15 accessions) from both the first and second rounds of tests were re-inoculated a third time as described previously and then transplanted into $10-\mathrm{cm}$ plastic pots in Metromix 360 . After 3 weeks of additional growth in the greenhouse, the plants were transferred to 2-gallon $(7.6 \mathrm{~L})$ plastic pots filled with Metromix 360 and self-pollinated to generate an $\mathrm{S}_{1}$ population

Fon screen of $S_{I}$ populations. Viable $S_{1}$ seeds were obtained from 12 of the 15 resistant accessions (Table 2). Disease screening of the $12 \mathrm{~S}_{1}$ populations were performed as follows: 10 seeds were sown into a $1: 1: 1$ (v:v:v) mixture of Metromix 360, autoclaved sand, and vermiculite in 50-cell plug trays. Each cell was then inoculated by pipette with $20 \mathrm{~mL}$ of this inoculum suspension. Plants were maintained as described previously on greenhouse benches. Each plug tray cell was re-inoculated with an additional $15 \mathrm{~mL}$ of fresh inoculum $14 \mathrm{~d}$ after the original inoculation. Plants were rated as $1=$ healthy, $2=$ stunted/chlorotic, or $3=$ dead 5,21 , and $28 \mathrm{~d}$ after initial inoculation (Table 3 ). The screen was repeated.

Statistical analysis. Data on percentage of survivors from the initial two tests were arcsine transformed and analyzed using the PROC GLM procedure of SAS (SAS Institute Inc., Cary, NC). Means for each accession were separated using Fisher's protected least significant difference (LSD) $(P=0.05)$ (Table 1). Individual plant ratings collected over time using the 1-3 scale for the $S_{1}$ generation of each putatively resistant accession or the checks ('Charleston Grey' and 'Sugar Baby') were analyzed as repeatedmeasures data using the nonparametric analysis described by Brunner et al. (2002) and Shah and Madden (2004). The macro F1_LD_F1 was used to calculate the analysis of variance (ANOVA)-type statistic to test for the overall effect of a factor on disease severity and for testing pairwise comparisons of the relative treatment effects (RTE) within factors (Akritas and Brunner, 1997). In short, the relative effect for the $i$ th treatment, $p_{i}$, describes the stochastic tendency of the normalized distribution $F_{i}(x)$ for the random variable $X_{i}$ relative to the weighted average of all the $F_{i}(x) \mathrm{s}$ in the experiment. An estimate of the relative treatment effect can be obtained from the observed midranks. If $R_{i k}$ is the rank of $X_{i k}$ among all $N$ observations, the mean rank for the $i$ th treatment is estimated by $\bar{R}_{i \bullet}=1 / n_{i} \sum_{n_{i}} R_{i}$, where $n_{i}$ is the number observations in the $i$ th treatment, and the relative treatment effect is estimated as $\hat{p}_{i}=1 / N\left(\bar{R}_{i \bullet}-0.5\right)$ (Brunner et al., 2002; Shah and Madden, 2004). The macro files can be downloaded for free from the following web site (http://www.ams.med.uni-goettingen.de/ $\mathrm{de} / \mathrm{sof} / \mathrm{ld} / \mathrm{makros} . \mathrm{html}$ ). Pairwise comparison of the effects (RTE) of FW among the various 
Table 2. Fifteen Citrullus lanatus var. citroides accessions with the highest survival percentage in response to two controlled inoculations with Fusarium oxysporum f. sp niveum (Fon) Race 2 in two greenhouse tests and their origin and reported resistances to other pathogens.

\begin{tabular}{lcl}
\hline Accession & Country of collection & \multicolumn{1}{c}{ Reported phytopathogen resistance } \\
\hline PI 255136 & South Africa & None \\
PI 270564 & South Africa & None \\
PI 271769 & South Africa & Fon Races 1 and 2 (Dane et al., 1998) \\
PI 271779 & South Africa & Anthracnose (Sowell et al., 1980) \\
PI 296335 & South Africa & None \\
PI 296339 & South Africa & None \\
PI 299379 & South Africa & Anthracnose (Sowell et al., 1980) \\
PI 482246 & Zimbabwe & None \\
PI 482252 & Zimbabwe & Watermelon Mosaic Virus (GRIN, NGRP) \\
PI 482273 & Zimbabwe & Powdery mildew Race 2 (Tetteh et al., 2010); \\
& & Fon Race 2 (Boyhan et al., 2003) \\
PI 482276 & Zimbabwe & Gummy stem blight (Gusmini et al., 2005) \\
PI 482277 & Zimbabwe & Powdery mildew race 2 (Tetteh et al., 2010) \\
PI 482279 & Zimbabwe & Bacterial fruit blotch (Hopkins and Thompson, 2002) \\
PI 482282 & Zimbabwe & None \\
PI 482331 & Zimbabwe & None \\
\hline
\end{tabular}

Table 3. Responses of the first self-pollinated (S1) generation of 12 Citrullus lanatus var. citroides accessions and two watermelon cultivars to controlled inoculation with Fusarium oxysporum f. $\mathrm{sp}$. niveum Race 2 in two greenhouse tests as expressed by relative treatment effect (RTE), disease rating $28 \mathrm{~d}$ post-inoculation, and percent survival of plants.

\begin{tabular}{|c|c|c|c|c|c|c|c|c|c|c|c|}
\hline \multirow[b]{2}{*}{ Accession } & \multicolumn{5}{|c|}{ First screen } & \multicolumn{5}{|c|}{ Second screen } & \multirow{2}{*}{$\begin{array}{c}\text { Mean } \\
\text { survival } \\
(\%)\end{array}$} \\
\hline & $\mathrm{RTE}^{\mathrm{z}}$ & & $\begin{array}{c}\text { Final } \\
\text { rating }^{\mathrm{y}}\end{array}$ & & $\begin{array}{c}\text { Survival }^{\mathrm{x}} \\
(\%)\end{array}$ & RTE & & $\begin{array}{l}\text { Final } \\
\text { rating }\end{array}$ & & $\begin{array}{c}\text { Survival } \\
(\%)\end{array}$ & \\
\hline PI 482246 & 0.319 & $\mathrm{~g}^{\mathrm{W}}$ & 1.2 & $\mathrm{f}$ & 100 & 0.341 & de & 1.4 & de & 100 & 100 \\
\hline PI 482252 & 0.319 & $\mathrm{~g}$ & 1.2 & $f$ & 100 & 0.327 & e & 1.3 & $\mathrm{e}$ & 100 & 100 \\
\hline PI 271769 & 0.458 & ef & 1.7 & ef & 89 & 0.515 & $\mathrm{bc}$ & 1.9 & cde & 89 & 89 \\
\hline PI 296335 & 0.471 & ef & 1.9 & de & 75 & 0.406 & de & 1.4 & de & 100 & 88 \\
\hline PI 296339 & 0.438 & f & 2.1 & cde & 57 & 0.428 & de & 1.9 & cde & 88 & 73 \\
\hline PI 482279 & 0.488 & ef & 2.1 & cde & 63 & 0.452 & $\mathrm{~cd}$ & 2.0 & bcd & 75 & 69 \\
\hline PI 482276 & 0.435 & fg & 1.7 & ef & 89 & 0.438 & $\mathrm{~cd}$ & 2.2 & bc & 44 & 67 \\
\hline PI 299379 & 0.534 & de & 2.1 & cde & 75 & 0.554 & $\mathrm{bc}$ & 2.2 & bc & 56 & 66 \\
\hline PI 271779 & 0.547 & de & 2.1 & cde & 63 & 0.508 & bcd & 2.0 & bcd & 67 & 65 \\
\hline PI 270564 & 0.609 & $\mathrm{~b}$ & 2.3 & bcd & 67 & 0.607 & $\mathrm{~b}$ & 2.4 & $\mathrm{abc}$ & 56 & 62 \\
\hline PI 482331 & 0.599 & bc & 2.4 & bcd & 50 & 0.580 & $\mathrm{~b}$ & 2.4 & $a b c$ & 50 & 50 \\
\hline PI 482282 & 0.592 & bcd & 2.6 & $a b c$ & 30 & 0.562 & $\mathrm{bc}$ & 2.4 & $\mathrm{abc}$ & 40 & 35 \\
\hline 'Charleston Grey' & 0.605 & $\mathrm{~b}$ & 2.8 & $\mathrm{ab}$ & 20 & 0.600 & $\mathrm{~b}$ & 2.6 & $a b$ & 44 & 32 \\
\hline 'Sugar Baby' & 0.695 & $\mathrm{a}$ & 3 & $\mathrm{a}$ & 0 & 0.703 & $\mathrm{a}$ & 3.0 & $\mathrm{a}$ & 0 & 0 \\
\hline
\end{tabular}

${ }^{\mathrm{z}} \mathrm{RTE}=$ relative treatment effect of each PI is based on the mean of three ratings taken on each PI at 5, 21, and $28 \mathrm{~d}$ after inoculation.

${ }^{\mathrm{y}}$ Final rating is based on the mean of the $1-3$ scale, where $1=$ healthy, $2=$ wilted/chlorotic, and $3=$ dead, rated $28 \mathrm{~d}$ after inoculation.

xPlants that did not die at $28 \mathrm{~d}$ after inoculation and rated less than 3 were considered as survivors.

${ }^{\mathrm{w}}$ Means followed by the same letter in a column are not significantly different $(P=0.05)$.

'Charleston Grey' = moderately susceptible control.

'Sugar Baby' = highly susceptible control.

accessions over time was done using the output generated by the mentioned SAS macros at $P=0.05$ (Table 3) (Akritas and Brunner, 1997; Brunner et al., 2002). Detailed descriptions of the statistical methods are provided by Shah and Madden (2004). The final ratings taken $28 \mathrm{~d}$ after inoculation were analyzed using the PROC GLM procedure of SAS. Means for each accession were separated using Fisher's protected LSD $(P=0.05)$.

\section{Results and Discussion}

Of the 110 C. lanatus var. citroides accessions examined in this study, 15 showed a significantly higher level of resistance than any of the other accessions to Fon Race 2 with a survival rate of $33.0 \%$ to $56.3 \% 28 \mathrm{~d}$ after the initial Fon inoculation (Tables 1 and 2). Most (67\%) of the 110 accessions had more surviving plants than all other accessions and cultivars tested and may be considered as potential sources of resistance (Table 2). These accessions had 33\% or greater survival rate with plants remaining healthy throughout the initial testing (Table 1). Here, PI 271769 and PI 296341, which were reported as resistant to Fon Race 2 (Dane et al., 1998; Martyn and Netzer, 1991), had a survival rate of $40.2 \%$ and $12.5 \%$, respectively (Table 1). Although PI 271769 showed intermediate resistance, PI 296341 was significantly more susceptible than the top performers. The most resistant line in the Boyhan et al. (2003) study, PI 534536, is listed as Cucumis melo var. melo in the Genetic Resources Information System and so would not be an actual host to this pathogen and thus was not included in our survey. On the other hand, PI 482273, listed as one of the 11 resistant watermelon PIs identified by Boyhan et al. (2003), was also found to be in the top 15 resistant lines in our study with $43.8 \%$ survival (Table 1 ). It is both interesting and troublesome that in the three previous published surveys as well as the one presented here, no consensus is found as to one or more resistant lines. This may in part be attributable to the particular isolate used for screening the lines, the type of inoculation method used, the age of the plant, and/or environmental conditions under which the assays were performed. On the other hand, it is evident from all of these studies that new putative sources of host plant resistance to Race 2 Fon exist among the $C$. lanatus var. citroides accessions. Healthy, inoculated plants from the 15 most resistant accessions were selfed and the $\mathrm{S}_{1}$ seed tested in subsequent experiments (Table 3). We obtained viable $\mathrm{S}_{1}$ seed from all but PI 255136, PI 482273, and PI 482277.

The ANOVA-type statistics indicated highly significant $(P \leq 0.00001)$ differences in FW development of the Race 2 inoculated $\mathrm{S}_{1}$ generations. A highly significant $(P<$ $0.00001)$ interaction between accessions and rating period (time, accession $\times \mathrm{T}$ ) was observed in both of the $S_{1}$ screens, indicating that disease progression occurred at different rates among the accessions and the susceptible checks. Disease progression was further evaluated by calculating the RTE, which takes into account each of the three ratings and compares them with the ratings from the other accessions. Disease progressed very rapidly on the susceptible control 'Sugar Baby' as indicated by the high relative treatment effect (0.695 and 0.703) for both screens and was significantly faster in progression than the other susceptible control, 'Charleston Grey', as well as the other accessions. All the tested $\mathrm{S}_{1}$ individuals of PI 482246 and PI 482252 survived in both screening procedures, and disease progress was significantly slower on these two accessions compared with the susceptible checks and susceptible accessions identified in this study. PI 482246 and PI 482252 also had the lowest final ratings of all other accessions in both screening procedures. Disease progress was 
significantly slower in PI $271769 \mathrm{~S}_{1}$ individuals when compared with either cultivar in the first screen and when compared with 'Sugar Baby' in the second screen. The PI $271769 \mathrm{~S}_{1}$ population had $89 \%$ survival in both screens. PI 271769 has previously been reported as a potential source of resistance by other researchers (Dane et al., 1998). Disease progress and final ratings were not significantly different from the control 'Charleston Grey' for $\mathrm{S}_{1}$ generation of PI 482282 and PI 482331. Highly significant correlations ( $P \leq$ $0.0001)$ between the RTE and final ratings were observed in the first $(r=0.95)$ and the second $(r=0.94) \mathrm{S}_{1}$ screens. Similarly, the number of survivors was also significantly $(P \leq 0.0001, r=0.85)$ correlated with the RTE in both the $\mathrm{S}_{1}$ screens.

Of the 15 resistant accessions chosen for tests of the $S_{1}$ generation, all were collected from southern Africa, the center of origin of Citrullus spp. (Table 2). Eight of these accessions were collected in Zimbabwe: PI 482246, PI 482252, PI 482279, PI 482282, PI 482331, PI 482273, PI 482276, and PI 482277, whereas seven accessions were collected in South Africa: PI 255136, PI 296335, PI 296339, PI 299379, PI 270564, PI 271769, and PI 271779. The exact lineage or initial origin of these accessions is not known. How the genetic make-up of the accessions reported here compares with that of PI 296341 or PI 271769 also is unknown. Although all of the identified resistant germplasm is from the African continent, the collection points differ. Both PI 296341 and PI 271769 were acquired from South Africa, whereas the two most resistant accessions reported here, PI 482246 and PI 482252, are from Zimbabwe.

Zhang and Rhodes (1993) using controlled crosses of PI 296341 with the cultivar New Hampshire Midget and root inoculations with Fon Race 2 reported a 13 susceptible:three resistant ratio, but their actual data are also an acceptable fit to a $3: 1$ ratio $\left(\chi^{2}=\right.$ $1.86, P=0.18)$ expected for the simpler, single gene model. Unfortunately, they do not include the test cross to the resistant parent, which would be expected to segregate one susceptible:one resistant in a single-gene model or two susceptible:one resistant in a twogene model. This omission, combined with the vagueness of the statistics used and a less than perfect fit to either a $3: 13$ or a $1: 3$ ratio, makes it difficult to determine inheritance. Genetic control of resistance to Fon Race 2 in PI 296341-FR has not been determined with any certainty.

Xu et al. $(1999,2000)$ studied the heritability of resistance to Fon Race 1 in PI 296341 and reported that the resistance is conditioned by a single dominant gene. Henderson et al. (1970) also found that Fon Race 1 resistance was conditioned by a single gene in the resistant watermelon cultivar Summit. Netzer and Weintall (1980) examined $F_{1}, F_{2}$, $\mathrm{F}_{3}$, and backcross progenies of crosses between the Fon Race 1-susceptible watermelon cultivar Mallali and two resistant cultivars, Calhoun Gray and Summit, concluding that the resistance is conferred by a single dominant gene,
Fo-1 (Wehner, 2008). These observations indicate that there may be more than one FW resistance gene in PI 296341.

Several other studies of fusarium resistance in cucurbits have identified the involvement of single dominant genes for resistance. In the cucurbit Cucumis melo (cantaloupe), resistance to the FW pathogen Fusarium oxysporum f. sp. melonis Race 1 is conferred by a single dominant gene (Fom-2) and resistance to Race 2 is controlled by another dominant gene (Fom-1) with both genes also conferring resistance to Race 0 (Joobeur et al., 2004; Schreuder et al., 2000; Wang et al., 2000; Wechter et al., 1995, 1998; Zink and Thomas, 1990). The confusion and difficulties associated with determining the inheritance of resistance to Fon Race 2 in PI 296341 may be why, to date, no markers for this resistance have been reported and why no commercial cultivars with resistance to Race 2 have been developed.

Work is currently being carried out to determine the genetics involved in resistance in a number of these accessions. These studies should lead to the identification and development of molecular markers linked to FW Race 2 resistance for use in introgression of the identified resistance into breeding lines and ultimately watermelon cultivars.

\section{Literature Cited}

Akritas, M.G. and E. Brunner. 1997. A unified approach to rank tests for mixed models. J. Statist. Plann. Inference 61:249-277.

Boughalleb, N. and M. El Mahjoub. 2007. Frequency of Fusarium oxysporum f. sp. niveum and $F$. solani f. sp. cucurbitae from watermelon seeds and their effect on disease incidence. Research Journal of Parasitology. 2:32-38

Bouhot, D. 1981. Some aspects of the pathogenic potential in formae specials and races of Fusarium oxysporum on Cucurbitaceae, p. 318-326. In: Nelson, P.E., T.A. Toussoun, and R.J. Cook (eds.). Fusarium: Disease, biology, and taxonomy. Pennsylvania State University Press, University Park, PA.

Boyhan, G.E., D.B. Langston, D.M. Granberry, P.M. Lewis, and D.O. Linton. 2003. Resistance to fusarium wilt and root-knot nematode in watermelon germplasm. Cucurb. Gen. Coop. Rpt. 26:18-25.

Brunner, E., S. Domhof, and F. Langer. 2002. Nonparametric analysis of longitudinal data in factorial experiments. John Wiley \& Sons, New York, NY.

Bruton, B.D. and J.P. Damicone. 1999. Fusarium wilt of watermelon: Impact of race 2 of $\mathrm{Fusa}$ rium oxysporum f. sp. niveum on watermelon production in Texas and Oklahoma. Subtrop. Plant Sci. 51:4-9.

Bruton, B.D., W.W. Fish, and D.D. Langston. 2008. First report of Fusarium wilt caused by Fusarium oxysporum f. sp. niveum race 2 in Georgia watermelons. Plant Dis. 92:983.

Bruton, B.D., C.L. Patterson, and R.D. Martyn. 1988. Fusarium wilt (Fusarium oxysporum f. sp. niveum race 2) of watermelons in Oklahoma. Plant Dis. 72:734.

Dane, F., L.K. Hawkins, J.D. Norton, Y.-S. Kwon, and Y.-H. Om. 1998. New resistance to Race 2 of Fusarium oxysporum F. sp. niveum in watermelon. Cucurbit Genet. Coop. Rpt. 21:37-39.
Egel, D.S., R. Harikrishnan, and R.D. Martyn. 2005. First report of Fusarium oxysporum f sp. niveum race 2, causal agent of fusarium wilt of watermelon, in Indiana. Plant Dis. 89:108.

Gusmini, G., R. Song, and T.C. Wehner. 2005. New sources of resistance to gummy stem blight in watermelon. Crop Sci. 45:582-588.

Henderson, W.R., S.F. Jenkins, and J.O. Rawlins. 1970. The inheritance of fusarium wilt resistance in watermelon, Citrullus lanatus (Thunb.) Mansf. J. Amer. Soc. Hort. Sci. 95:276-282.

Hopkins, D.L., and C.M. Thompson. 2002. Evaluation of Citrullus sp. Germplasm for resistance to Acidovorax avenae subsp. citrulli. Plant Dis. 86:61-64.

Jarret, R.L., L.C. Merrich, T. Holms, J. Evans, and M.K. Aradhya. 1997. Simple sequence repeats in watermelon [Citrullus lanatus (Thumb.) Matsum. \& Nakai]. Genome 41:433-441.

Joobeur, T., J.J. King, S.J. Nolin, C.T. Thomas, and R.A. Dean. 2004. The Fusarium wilt resistance locus Fom-2 of melon contains a single resistance gene with complex features. Plant J. 39:283-297.

Keinath, A.P. and V.B. DuBose. 2009. First report of Fusarium oxysporum $\mathrm{f}$. sp. niveum race 2 in South Carolina watermelon fields. Phytopathology 99:S63 (Abstr.).

Keinath, A.P., R.L. Hassell, K.L. Everts, and X.-G. Zhou. 2010. Cover crops of hybrid common vetch reduce Fusarium wilt of seedless watermelon in the eastern United States. Online. Plant Health Prog. 20 Feb. 2012. <http://www. plantmanagementnetwork.org/sub/php/research/ 2010/vetch>.

Larkin, R.P., D.L. Hopkins, and F.N. Martin. 1990 Vegetative compatibility within Fusarium oxysporum f. sp. niveum and its relationship to virulence, aggressiveness, and race. Can. J. Microbiol. 36:352-358.

Levi, A., C.E. Thomas, A.P. Keinath, and T.C. Wehner. 2001. Genetic diversity among watermelon (Citrullus lanatus and Citrullus colocynthis) accessions. Genet. Resour. Crop Evol. 48:559-566

Levi, A., W.P. Wechter, L.M. Massey, L. Carter, and D. Hopkins. 2011. Genetic linkage map of Citrullus lanatus var. citroides chromosomal segments introgressed into the watermelon cultivar Crimson Sweet (Citrullus lanatus var. lanatus) genome. Amer. J. Plant Sci. 2:93-110.

Martyn, R.D. 1985. An aggressive race of Fusarium oxysporum $\mathrm{f}$. $\mathrm{sp}$. niveum new to the United States. Plant Dis. 69:1007.

Martyn, R.D. 1987. Fusarium oxysporum f. sp. niveum race 2: A highly aggressive race new to the United States. Plant Dis. 71:233-236.

Martyn, R.D. 1996. Fusarium wilt of watermelon, p. 13-14. In: Zitter, T.A., D.L. Hopkins, and C.E. Thomas (eds.). Compendium of cucurbit diseases. APS Press, American Phytopathological Society, St. Paul, MN.

Martyn, R.D. and B.D. Bruton. 1989. An initial survey of the United States for races of Fusarium oxysporum $\mathrm{f}$. sp. niveum. HortScience 24: 696-698.

Martyn, R.D. and D. Netzer. 1991. Resistance to races 0,1 , and 2 of fusarium wilt of watermelon in Citrullus sp. PI-296341-FR. HortScience 26: 429-432.

Michail, S.H., M.A. Abdel Rehim, A.M. Tarabeih, and M.A. Aly. 2002. Effect of fusarium seedborne infection levels on watermelon wilt incidence. Acta Phytopathol. Entomol. Hung. 34 347-351.

Netzer, D. 1976. Physiological races of soil population levels of fusarium wilt of watermelon Phytoparasitica 4:131-136. 
Netzer, D. and R.D. Martyn. 1989. PI 296341, a source of resistance in watermelon to race 2 of Fusarium oxysporum f. sp. niveum. Plant Dis. 73:518.

Netzer, D. and C. Weintall. 1980. Inheritance of resistance in watermelon to race 1 of Fusarium oxysporum f. sp. niveum. Plant Dis. 64:853854.

Owens, J.H. 1955. Fusarium wilt of cucumber. Phytopathology 45:435-439.

Owens, J.H. 1956. Cucumber wilt, caused by Fusarium oxysporum $\mathrm{f}$. sp. cucumerinum $\mathrm{n}$. f. Phytopathology 46:153-157.

Schreuder, W., S.C. Lamprecht, and G. Holz. 2000. Race determination and vegetative compatibility grouping of Fusarium oxysporum f. sp. melonis from South Africa. Plant Dis. 84:231234.

Shah, D.A. and L.V. Madden. 2004. Nonparametric analysis of ordinal data in designed factorial experiments. Phytopathology 94:33-43.

Sowell, G., Jr., B.B. Rhodes, and J.D. Norton. 1980. New sources of resistance to watermelon anthracnose. J. Amer. Soc. Hort. Sci. 105:197-199.

Tetteh, A.Y., T.C. Wehner, and A.R. Davis. 2010. Identifying resistance to powdery mildew $2 \mathrm{~W}$ in the USDA-ARS watermelon germplasm collection. Crop Sci. 50:933-939.

Thies, J.A. and A. Levi. 2007. Characterization of watermelon (Citrullus lanatus var. citroides) germplasm for resistance to root-knot nematodes. J. Nematol. 42:1530-1533.

Wang, Y.H., C.T. Thomas, and R.A. Dean. 2000. Genetic mapping of a fusarium wilt resistance gene (Fom-2) in melon (Cucumis melo L.). Mol. Breed. 6:379-389.

Wechter, W.P., R.A. Dean, and C.T. Thomas. 1998. Development of sequence-specific primers that amplify a $1.5-\mathrm{kb}$ DNA marker for race 1 fusarium wilt resistance in Cucumis melo L. HortScience 33:291-292.

Wechter, W.P., M.P. Whitehead, C.T. Thomas, and R.A. Dean. 1995. Identification of a randomly amplified polymorphic DNA marker linked to the Fom 2 fusarium wilt resistance gene in muskmelon MR-1. Phytopathology 85:12451249.

Wehner, T.C. 2008. Overview of genes of watermelon, p. 79-89. In: Pitrat, M. (ed.). Cucurbitaceae 2008. Proc. IX ${ }^{\text {th }}$ EUCARPIA meeting on genetics and breeding of Cucurbitaceae, Il'institut National de la Recherche Agronomique, Avignon, France, 21-24 May 2008.

Xu, Y., X.X. Ouyang, H.Y. Zhang, and Y.J. Wang. 1999. Identification of molecular markers linked to race 1 fusarium wilt resistance gene in watermelon wild germplasm PI 296341. Acta Bot. Sin. 41:952-955.

Xu, Y., H.Y. Zhang, G.B. Kang, Y.J. Wang, and H. Chen. 2000. Studies of molecular marker- assisted selection for resistance to fusarium wilt in watermelon (Citrullus lanatus) breeding. Acta Genet. Sin. 27:151-157.

Zhang, X.P. and B.B. Rhodes. 1993. Inheritance of resistance to races 0,1 , and 2 of Fusarium oxysporum f. sp. niveum in watermelon(Citrullus sp. PI 296341). Cucurbit Genet. Coop. Rpt. 16:77-78.

Zhou, X.G. and K.L. Everts. 2001. First report of the occurrence of Fusarium oxysporum f. sp. niveum in commercial watermelon production areas of Maryland and Delaware. Plant Dis. $85: 1291$.

Zhou, X.G. and K.L. Everts. 2003. Races and inoculum density of Fusarium oxysporum f. sp. niveum in commercial watermelon fields in Maryland and Delaware. Plant Dis. 87:692-698.

Zhou, X.G. and K.L. Everts. 2007. Characterization of a regional population of Fusarium oxysporum f. sp. niveum by race, cross pathogenicity, and vegetative compatibility. Phytopathology 97:461-469.

Zhou, X.G., K.L. Everts, and B.D. Bruton. 2010 Race 3, a new and highly virulent race of Fusarium oxysporum $\mathrm{f}$. sp. niveum causing fusarium wilt in watermelon. Plant Dis. 94:92-98.

Zink, F.W. and C.E. Thomas. 1990. Genetics of resistance to Fusarium oxysporum f. sp. melonis races 0,1 , and 2 in muskmelon line MR-1. Phytopathology 80:1230-1232. 